\title{
The Effect of Icky Shuffle and Diagonal Quick Slalom Exercises Using the Ladder Drill Method on Agility
}

\author{
Sabat Syah Bandang ${ }^{1}$, Purwono Sidik Permono ${ }^{2}$ \\ \{sabatsyah3@students.unnes.ac.id ${ }^{1}$, purwonosidik@mail.unnes.ac.id ${ }^{2}$ \} \\ Universitas Negeri Semarang, Indonesia ${ }^{1,2}$
}

\begin{abstract}
Player of PS. Pemda Surakarta $\neg$ U-19 have less agility. The research objective was to determine the effect of the icky shuffle and diagonal quick slalom exercises using the ladder drill method. The research use the experimental method. Data were taken through pretest and posttest. The sample was 20 players of U-19 soccer players of PS. Pemda Surakarta. The results 1) There is an effect of icky shuffle training using the ladder drill method on the agility, 2) There is an effect of diagonal quick slalom training using the ladder drill method on the agility, 3) The ladder drill diagonal quick slalom is better at increasing agility. Conclusion: The icky shuffle ladder drill exercise and diagonal quick slalom ladder drill exercise both had an effect on increasing agility in U19 soccer players of PS. Pemda Surakarta, with an average difference in posttest of 0,44 seconds.
\end{abstract}

Keywords: : exercise, agility, ladder drill.

\section{Introduction}

One of the most important components to support the performance of soccer athletes on the field is that it requires a high level of agility, some forms of activity on the field that require agility when dribbling the ball quickly towards the goal past several opponents who oversee areas with certain formations. Agility is very decisive in order to break through to avoid obstacles from the opponent in order to enter the opponent. In addition, agility is an important aspect for athletes in order to maintain balance and reduce the risk of injury when running on the field. Of course, this physical component must use the right training method in order to achieve the previously determined or desired goals. One method is to use a ladder drill.

Practice ladder continuously using the equipment that is included in the ladder which is on a flat plane or floor. Ladder training is used to increase speed, agility and coordination over time, if done every day it can improve leg performance. Ladder drill is very helpful for players to improve speed, agility, and coordination. Ladder training also helps the trainer determine the various variations of the exercises that are in the ladder training so that the exercise is not boring. Ladder exercises also help in improvising various aspects of the movement. There are various kinds of movements in the ladder drill depending on what you want to be the target or goal in each exercise. Anyone can practice the ladder exercise with simple movements, such as with strong forward, backward, and sideways movements, lifting the knee high while running sideways. 
The movements in the ladder drill used to achieve the objectives of the study are the icky shuffle ladder drill and diagonal quick slalom. The icky shuffle is carried out by means of a movement that starts from the left side behind the ladder, then the right foot goes first followed by the left foot, then the right foot exits to the right of the first box accompanied by the left foot advancing forward, then the right foot follows the left foot, and the left foot. exit to the left side of the box, and so on. Whereas the diagonal quick slalom starts with standing from the left side of the back of the ladder then small jumps into the first box, then exits to the right side, then enters the second box, then exits to the left side, and so on while still fast small jumps using both feet in a row. at the same time. These two training methods using ladder drills can be another option for a coach to increase the agility of the players because this method is considered quite effective.

In the observations of researchers at PS. The local government of Surakarta on Saturday, February 22, 2020, the players have a low level of agility, meaning that there must be appropriate and routine training methods to be able to increase the agility of the players. According to the head coach of PS. The local government of Surakarta, Fajar Aryoko, indeed the agility of the players is not good because within a week, the players are only given agility training once out of three exercises, and even then they only use cones, not infrequently even in a week they are not given at all.

\section{Methods}

This study used a quasi-experimental research method, meaning that the sample was not quarantined or not boarded out. According to Nana Syaodih Sukmadinata (2012: 194) experimental research is the most complete quantitative research approach, in the sense that it fulfills all the requirements for testing cause-effect relationships. To test the effect or causal relationship of one or more things or variables. The research design used in this study was a Two Group Pretest and Posttest Design, namely a research design that contained a pretest before being given treatment and a posttest after being given experimental treatment which was carried out in two groups. Then group 1 was given icky shuffle treatment using the ladder drill method and group 2 was given diagonal quick slalom treatment using the ladder drill method.

This study uses two variables, namely the independent variable and the dependent variable. The independent variable (independent variable) or variable $\mathrm{X}$ is a variable that is seen as the cause of the emergence of the dependent variable which is suspected to be the result. Meanwhile, the dependent variable or variable $\mathrm{Y}$ is the predictive variable (effect), which varies according to changes in the independent variables. According to Sugiyono (2010: 30 ), based on the relationship between one variable and another, the variables in this study are as follows:

This variable is often referred to as the stimulus, predicator, and antecedent variable. The author determines the independent variables in this study are Icky Shuffle Exercise (X1) and Diagonal Quick Slalom Exercise (X2). The dependent variable is the variable that is influenced or which is the result of the existence of the independent variable in accordance with the problem to be investigated, so what will be the dependent variable is the PS Soccer Player Agility. Regional Government of Surakarta U-19. According to Margono (2004: 118), population is all data that is of concern within a specified scope and time. The population of this study were PS soccer players. The local government of Surakarta U-19, with a total of 20 
players. Margono (2004: 121) states that the sample is part of the population. The sampling technique used in this study was the total sampling technique, which included all PS players. The local government of Surakarta U-19 consists of 20 players.

The sampling technique used in this study was the total sampling technique, which included all PS players. The local government of Surakarta U-19 consists of 20 players. All samples were subjected to a pretest to determine the treatment group, then the results of the pretest scores were ranked from the first to the last rank. Then paired (matced) with the ABBA pattern in which there were two groups, group one was given the ladder drill treatment with the icky shuffle model and group two was given the ladder drill treatment with the diagonal quick slalom model. The sample distribution technique in this study uses ordinal pairing. Ordinal pairing is the division of the group into two with the aim of both having the same or the same abilities, Sugiyono (2007: 61), the ordinal pairing stage is that after the sample does a pretest, the pretest results are arranged based on ranking and paired (matced) with the AB-BA pattern.

The research instrument is a tool used to measure observed natural and social phenomena (Sugiyono, 2012: 148). The test will be used to measure the agility of PS soccer players. Regional Government of Surakarta U-19, namely the Illinois Agility Run Test. This test aims to measure the agility of a person / athlete. The results of the study using the Illinois Agility Run Test instrument showed the validity and reliability of 0.90 and 0.94 .

Data analysis techniques include: 1) normality test, 2) homogeneity, 3) t-test analysis technique. The normality test in this study uses the chi squared formula (Sutrisno Hadi, 2003: 317 ), which is to find out whether the data distribution deviates from the normal distribution. The calculation of data normality in this study used Kolmogorov Smirnov with the help of SPSS. The homogeneity test is useful for testing the similarity between groups of data. The homogeneity test was carried out by the F test with the help of SPSS. The homogeneity test is meant by dividing the largest variance by the smallest variance obtained. The data analysis technique used was the Paired Sample t-test analysis with the help of SPSS 24.

\section{Result and Discussion}

The data used to analyze the research data were the agility of PS soccer players. Pemda Surakarta U-19 before and after being given the icky shuffle ladder drill training and diagonal quick slalom ladder drill. It is found that the amount of pretest data is 20 . The minimum value obtained is 15.82 and the maximum value is 18.33 . The number of values that can be obtained is 339.69 with an average of 16.9845. The standard deviation obtained is 0.47165 with a variant of 0.456 . The description of the pretest research results is also presented in the frequency distribution by first determining the number of classes $(\mathrm{KI})=1+3,3 \log \mathrm{N}=1+$ $3,3 \log 20=5$; range $(\mathrm{R})=$ maximum value-minimum value $=18.33-15.82=2.51$; and class length $(\mathrm{P})=\mathrm{R} / \mathrm{KI}=2.51 / 5=0.502$.

Posttest data obtained as many as 20 . Minimum value 14.05 , maximum value 17.19 , the amount obtained is 304.98 with an average of 15.2490 , a standard deviation of 0.76489 with a variant of 0.585 . The description of the posttest research results is also presented in the frequency distribution by first determining the number of classes $(\mathrm{KI})=1+3,3 \log \mathrm{N}=1+$ $3,3 \log 20=5$; range $(\mathrm{R})=$ maximum value-minimum value $=17.19-14.05=3.14$; and class length $(\mathrm{P})=\mathrm{R} / \mathrm{KI}=3.14 / 5=0.628$. 
The normality test is intended to see whether the data obtained is normal or abnormal. The criteria for testing the normality of the data obtained are, if the sig value is $>0.05$ or $5 \%$, the data obtained is declared normal, and if the sig $<0.05$ or $5 \%$, the data obtained is declared abnormal. The normality test using the One Sample Kolmogorov Smirnov Test obtained the pre-test sig value of the icky shuffle group $0.124>0.05$, thus it can be said that the pretest data is normally distributed and the posttest sig value of the icky shuffle group is $0.159>0.05$, thus it can be said that the posttest data is normally distributed . Likewise, the pretest results of the diagonal quick slalom group had a sig value of $0.129>0.05$, meaning that the pretest data were normally distributed and also the posttest sig values of the diagonal quick slalom group were $0.103>0.05$, meaning that the posttest data were normally distributed. The results of this analysis were used as a consideration in further analysis using parametric statistics.

The homogeneity test is intended to determine whether the data that has been obtained is homogeneous or not different, the criteria used to determine the homogeneity of the data obtained is if the significance value is more than 0.05 , it can be said that the two variants are homogeneous. The results obtained from the pretest data sig value of $0.708>0.05$ and the posttest data $0.348>0.05$, it can be concluded that the group has homogeneous variance.

Data collection for the pretest and posttest Illinois Agility Run Test was carried out twice, taking the best time. The results of the research on the level of agility of PS soccer players. The local government of Surakarta U-19 through agility training with Icky Shuffle and Diagonal Quick Slalom using the ladder drill method is described as follows:

Based on the results of the research analyzed using SPSS 24, it was found that the icky shuffle group pretest had the minimum value $=15.82$, the maximum value $=18.33$, the average $=17.042$, the standard deviation was 0.73507 , while for the icky shuffle group posttest the value minimum $=14.25$, maximum value $=17.19$, average 15.47 , standard deviation $=0.85282$. Based on the results of the research analyzed using SPSS 24, it was found that the pretest of the Diagonal Quick Slalom group had the minimum value $=15.91$ maximum value $=17.85$ average $=16.927$ with standard deviation $=0.64450$ while for the posttest group Diagonal Quick Slalom the minimum value $=14.05$, the maximum value $=$ 16.03 average $=15.03$ standard deviation $=0.63266$

The analysis of the improvement in the results of the ability to dribble was carried out to determine how much the treatment in the icky shuffle group and the diagonal quick slalom group was able to increase the agility results. The results of the calculation of increased agility results can be seen in the below. From the above, it is found that the percentage increase in agility results in the group given icky shuffle training obtained a change of 1.572 with a percentage of $9.22 \%$, while the group given the diagonal quick slalom exercise gained an increase of 1.897 with a percentage of $11.20 \%$. For more details, the following diagram is presented for the increase in agility results. 


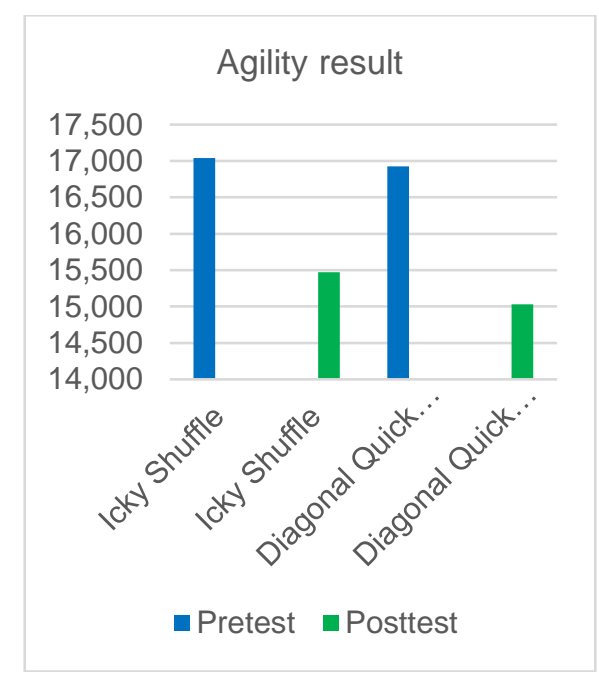

Fig. 1. Diagram of increasing agility

The difference test of the two mean posttest data in this study was used to determine whether there was a difference in the results of the agility ability between the icky shuffle group and the diagonal quick slalom group after being given different exercises. Where the icky shuffle group was given the icky shuffle exercise while the diagonal quick slalom group was given the diagonal quick slalom exercise.

The hypothesis used: There was no difference in the posttest results between the Icky Shuffle group and the Diagonal Quick Slalom group after being given different exercises (Ho). There is a difference in the posttest results between the Icky Shuffle group and the Diagonal Quick Slalom group after being given different exercises (Ha).

In this study using a confidence level $=95 \%$ or $(\square)=0.05$. The results of the calculation of the difference between the two mean post test data are presented in the below: The number of samples for each group is 10 and $\mathrm{t}=2.26$, with the following decision-making criteria: $\mathrm{H} 0$ accepted if - ttabel $\leq$ thitung $\leq$ ttabel atau sig $\geq 0,05$. H0 rejected if (thitung $<-$ ttabel atau thitung $>$ ttabel) atau sig $<0.05$. From the t-test result above, it can be seen that the t-count is 1.310 and the $\mathrm{t}-(\mathrm{df}=9)=2.26$, the significance value of $\mathrm{p}$ is 0.348 . Because $\mathrm{t}$ count $1.310<\mathrm{t}$ $=2.26$ and sig. $0.348>0.05$, meaning that there is no difference in posttest results between the Icky Shuffle and Diagonal Quick Slalom groups after being given different exercises or the Icky Shuffle and Diagonal Quick Slalom groups both have a good effect on the agility results of PS soccer players. Regional Government of Surakarta U-19.

Based on the analysis, it shows that the icky shuffle group has an average posttest of 15.469 seconds, and the diagonal quick slalom group is 15.029 seconds, with an average difference of 0.44 seconds. Thus, there is no difference between the icky shuffle and the diagonal quick slalom for increasing the agility ability of PS soccer players. The local government of Surakarta U-19, or icky shuffle and diagonal quick slalom training both have an influence on the agility ability of PS soccer players. The local government of Surakarta U19 can be identified through the posttest between the icky shuffle and diagonal quick slalom training groups.

This study aims to determine the effect of the icky shuffle ladder drill and diagonal quick slalom ladder drill on the agility of PS soccer players. Regional Government of Surakarta U19 in 2020. A player who has good agility has several advantages, including: easy to make 
difficult movements, not easy to fall or injure, and supports the techniques he uses, especially the dribbling technique (Joko Purwanto, 2004 : 41). The characteristics of agility can be seen from the ability to move quickly, change direction and position, avoid collisions between players and the ability to dodge opposing players on the field. The ability to move changes direction and position depending on the situation and conditions faced in a relatively short time and quickly.

Based on the results of the $t$ test, it shows that the ladder drill icky shuffle exercise and the diagonal quick slalom ladder drill exercise have the same effect on increasing agility in PS soccer players. Pemda Surakarta U-19, with an average difference in posttest of 0.44 seconds. Based on the research data processing, it can be seen that the initial conditions of the two groups, namely the experimental group 1 and the experimental group 2, did not have a significant difference. Evidenced by the results of the t-test, the value of $t$ count $=0.372$ with $\operatorname{sig}=0.714>0.05$. It can be concluded that there is no difference in the results of increasing agility between the experimental group 1 and the experimental group 2 at the pretest (before treatment) on the players.

After the pretest was carried out, the treatment process was given where the experimental group had 1 ladder drill icky shuffle and the experimental group 2 ladder drills diagonal quick slalom. Each group was given treatment in the same period of time where the experimental group 1 ladder drill icky shuffle passed 15 ladder drill boxes, while the experimental group 2 ladder drills diagonal quick slalom passed 15 ladder drill boxes and with the same repetitions and sets. After the treatment was completed in 14 meetings, a posttest was carried out.

Giving training results obtained from the two groups, namely the experimental group 1 ladder drill icky shuffle and the experimental group 2 ladder drill diagonal quick slalom to PS soccer players. The Regional Government of Surakarta U-19 in 2020 both had an impact on agility results but did not differ significantly. Although not significantly different, the provision of diagonal quick slalom ladder drills had better results than giving exercises with the icky shuffle ladder drill group. This is because the diagonal quick slalom ladder drill is more effective and optimal for training the results of agility in soccer players. Because with the diagonal quick slalom ladder drill exercise, the movement is more or less the same as the existing test instrument compared to the icky shuffle ladder drill, because with that, a level of speed of moving can be done effectively. Repeating an exercise movement is very important. By repeating a movement continuously, skill movements can be mastered automatically. A skill that is mastered well will make the movements more effective and efficient.

Whereas in the ladder drill icky shuffle exercise, the movements carried out are only fast movements and do not have explosive power like the movements in the research instrument. However, in this case the ladder drill icky shuffle exercise has advantages in terms of agility and foot speed in moving.

\section{Conclusion}

Based on the results of data analysis, description, examination of research results, and discussion, conclusions can be drawn, namely: 1) There is an effect of icky shuffle training using the ladder drill method on the agility of PS soccer players. Regional Government of Surakarta U-19 with $t$ count $16.753>\mathrm{t} 2.26$ and sig. $0.000<0.05$, with a percentage increase of $9.22 \%, 2$ ) There is an effect of diagonal quick slalom training using the ladder drill method on the agility of PS soccer players. Regional Government of Surakarta U-19 with t count 
17,758> t 2.26 and sig. $0.000<0.05$, with a percentage increase of $11.20 \%$, and 3) Quick slalom diagonal training using the ladder drill method is better at increasing agility in PS soccer players. Pemda Surakarta U-19 rather than ladder drill icky shuffle, with an average posttest difference of 0.44 seconds.

Based on the research conclusions above, there are several suggestions that can be conveyed, namely: 1) For PS soccer players. The Regional Government of Surakarta U-19 should continue to strive to improve agility skills, so that it will improve the ability to play soccer and achieve maximum achievements, 2) For coaches, to increase the agility of their athletes, in order to provide interesting and not monotonous training variations in agility training, 3) For trainers, it is better to improve agility by choosing diagonal quick slalom exercises with the ladder drill method, remembering that this is better for increasing leg speed, body control, and kinesthetic awareness, and coaches can apply icky shuffle exercises with the ladder drill method so that players don't feel saturated, 4) For other researchers, they should develop and perfect this research with better training methods.

\section{References}

[1] Afriwandi. 2009. Sports Medicine. Jakarta: EGC Medical Book.

[2] Budiwanto. 2012. Sports Exercise Methods. Malang: UM Press.

[3] Caldwell BP, Peters DM. Seasonal variation in physiological fitness of a semi-professional soccer team. Journal of Strength and Conditioning Research. 2009; 23(5): 1370-1377.

[4] Comfort P, Stewart A, Bloom L, Clarkson B. Relationships between strength, sprint, and jump performance in well-trained youth soccer players. J Strength Cond Res. 2014; 28: 173 \pm 177 .

[5] Kartal, R. (2016). Comparison of speed, agility, Anaerobic Strength and Anthopometric Characteristics in Male Soccer and Futsal Players. Journal of Educational and Training Studies. 23, 2154-2158.

[6] Miller, MG., Herniman, JJ., Richard, MD., Cheatham, CC \& Micheal, TJ (2006). Effect of six week plyometric training program on agility. Journal of Sports science and Medicine, 5(3), 459-465

[7] O'Reilly, J., Wong, S.H. The development of aerobic and skill assessment in soccer. Sports Medicine, 2012(42), 1029-1040.

[8] Reilly T, Gilbourne D. Science and soccer: a review of applied research in the soccer codes. Journal of Sports Sciences, 2003; 21: 693-705.

[9] Sporis G, Jukic I, Milanovic L, Vucetic V. Reliability and factorial validity of agility tests for soccer players. Journal of Strength and Conditioning Research. 2010; 24(3): 679-686.

[10] Tsitskarsis, G., Theoharopoulus, A., \& Garefis, A. (2003). Speed, speed dribble and agility of male basketball players playing in different positions. Journal of Human Movement Studies, 45, 21-30.

[11] Veale, J. P., Pearce, A. J., \& Carlson, J. S. (2010). Reliability and validity of a reactive agility test for Australian soccer. International 